\title{
The N-terminal Tail of C. elegans CENP-A Interacts with KNL-2 and is Essential for \\ Centromeric Chromatin Assembly
}

\author{
Christian de Groot ${ }^{* 1,2}$, Jack Houston*1, Bethany Davis ${ }^{1,2,6}$, Adina Gerson-Gurwitz ${ }^{1,2}$, \\ Joost Monen ${ }^{1,5}$, Karen Oegema1,3,4 , Andrew K. Shiau1,2,3, Arshad Desai ${ }^{1,3,4 @ ~}$
}

${ }^{1}$ Ludwig Institute for Cancer Research, San Diego Branch, La Jolla, CA

${ }^{2}$ Small Molecule Discovery Program, Ludwig Institute for Cancer Research, La Jolla, CA

${ }^{3}$ Section of Cell \& Developmental Biology, Division of Biological Sciences, University of California San Diego, La Jolla, CA

${ }^{4}$ Department of Cellular \& Molecular Medicine, University of California San Diego, La Jolla, CA

${ }^{5}$ School of Theoretical \& Applied Science, Ramapo College of New Jersey, Mahwah, NJ

${ }^{6}$ Dept. of Biology and Chemistry, Embry-Riddle Aeronautical University, Prescott, AZ

${ }^{*}$ co-first authors

@: Corresponding author

Email: abdesai@ucsd.edu

Phone:(858)-534-9698

Fax: (858)-534-7750

Address: CMM-E Rm 3052, 9500 Gilman Dr, La Jolla, CA 92093-0653

Running Title: Essential role of the N-Tail of CENP-A in C. elegans

Key words: centromere, chromosome segregation, mitosis, aneuploidy, kinetochore, CenH3, CENPA, histone tail 


\section{ABSTRACT}

2 Centromeres are epigenetically defined by the presence of the centromere-specific histone

3 H3 variant CENP-A. A specialized loading machinery, including the histone chaperone

4 HJURP/Scm3, participates in CENP-A nucleosome assembly. However, Scm3/HJURP is

5 missing from multiple lineages, including nematodes, which rely on a CENP-A-dependent

6 centromere. Here, we show that the extended N-terminal tail of C. elegans CENP-A contains

7 a predicted structured region that is essential for centromeric chromatin assembly. Removal

8 of this region of the CENP-A N-Tail prevents loading, resulting in failure of kinetochore

9 assembly and defective chromosome condensation. By contrast, the N-Tail mutant CENP-A

10 localizes normally in the presence of endogenous CENP-A. The portion of the N-Tail

11 containing the predicted structured region binds to KNL-2, a conserved SANTA and Myb

12 domain-containing protein (referred to as M18BP1 in vertebrates), that is specifically involved

13 in CENP-A chromatin assembly. This direct interaction is conserved in the related nematode

14 C. briggsae, despite divergence of the $\mathrm{N}$-Tail and $\mathrm{KNL}-2$ primary sequences. Thus, the

15 extended N-Tail of CENP-A is essential for CENP-A chromatin assembly in C. elegans and

16 partially substitutes for the function of Scm3/HJURP, in that it mediates an interaction of the

17 specialized histone fold of CENP-A with KNL-2. These results highlight an evolutionary

18 variation on centromeric chromatin assembly in the absence of a dedicated CENP-A-specific

19 chaperone/targeting factor of the Scm3/HJURP family. 


\section{INTRODUCTION}

Centromeres are specialized chromosomal loci that direct chromosome segregation.

22 In most species, active centromeres are defined by the presence of CENP-A, a histone

23 variant that replaces histone H3 in centromeric nucleosomes (Kixmoeller et al., 2020; Mitra

24 et al., 2020). CENP-A provides the physical foundation for assembly of the kinetochore, a

25 multiprotein complex mediating spindle microtubule attachment to chromosomes (Musacchio

26 and Desai, 2017). The cues leading to the centromere-restricted localization of CENP-A are

27 being actively investigated. The underlying centromeric DNA is not conserved and, with the

28 exception of budding yeasts, neither necessary nor sufficient to propagate CENP-A chromatin

29 (Allshire and Karpen, 2008; McKinley and Cheeseman, 2016).

A segment of the histone fold domain (HFD) of CENP-A, known as the CENP-A targeting domain (CATD), when transferred into canonical histone $\mathrm{H} 3$ is sufficient to confer centromere localization (Black et al., 2004). The CATD of CENP-A interacts with a CENP-Aspecific histone chaperone, known as 트olliday junction repair protein (HJURP) in vertebrates and Scm3 in fungi (Dunleavy et al., 2009; Foltz et al., 2009). This interaction is essential for CENP-A centromere targeting during mitotic exit (Foltz et al., 2009; Jansen et al., 2007). However, HJURP/Scm3 is not conserved in all species that build centromeres using CENPA, including insects and nematodes (McKinley and Cheeseman, 2016). In Drosophila melanogaster, there is compelling evidence that the unrelated protein Cal1 acts as a functional homologue of HJURP/Scm3 (Chen et al., 2014; Erhardt et al., 2008; Mellone et al., 2011). By contrast, in C. elegans, no HJURP/Scm3-like activity has been identified to date. In addition to promoting CENP-A nucleosome assembly, HJURP/Scm3 proteins target

42 the CENP-A/H4-HJURP/Scm3 prenucleosomal complex to the specific location of the 43 centromere by interaction with centromeric DNA/chromatin-bound targeting factors. In 44 budding yeast, the CBF3 complex specifically recognizes centromeric DNA and its subunit 
Ndc10 interacts with HJURP/Scm3 of the prenucleosomal complex to localize new CENP-A nucleosome assembly (Cho and Harrison, 2011). Outside of budding yeasts, where the CBF3

47 complex is not present, the Mis18 complex is the primary candidate for recognizing existing centromeric chromatin domains and targeting the deposition of new CENP-A via an interaction with HJURP/Scm3. The Mis18 complex is composed of Mis18 and/or KNL2/M18BP1, depending on the species: Mis18a, Mis18 \& \& M18BP1 in humans (Fujita et al.,

51 2007); Mis18 only in S. pombe (Hayashi et al., 2004; Pidoux et al., 2009; Williams et al., 52 2009); KNL-2 only in C. elegans (Maddox et al., 2007) and Arabidopsis (Lermontova et al.,

53 2013). S. pombe Mis18 and human Mis18 $\alpha / \beta$ interact with HJURP/Scm3 in vitro (Pan et al.,

54 2019; Pidoux et al., 2009; Wang et al., 2014) and Mis18 complex-mediated CENP-A recruitment can be bypassed by artificial tethering of HJURP/Scm3 to chromatin (Barnhart et al., 2011; Foltz et al., 2009; Ohzeki et al., 2012). In human cells, centromere localization of

57 the Mis18 complex precedes that of the CENP-A-H4-HJURP prenucleosomal complex during

58 mitotic exit-coupled new CENP-A chromatin assembly (Foltz et al., 2009; Jansen et al., 2007).

59 The Mis18 complex is proposed to recognize existing centromeric chromatin at least in part by binding to CENP-C, the reader of CENP-A nucleosomes that directs kinetochore assembly

61 (Kato et al., 2013; Moree et al., 2011). However, in C. elegans, KNL-2 localizes to chromatin

62 independently of CENP-C (Maddox et al., 2007) and, even in non-mammalian vertebrates,

63 the Mis18 complex directly recognizes CENP-A nucleosomes (French et al., 2017; Hori et al.,

64 2017). KNL-2/M18BP1 family proteins contain a conserved Myb-like DNA binding domain 65 and a SANTA domain whose functions independent of CENP-C association are unclear 66 (French and Straight, 2019; Maddox et al., 2007; Ohzeki et al., 2012; Zhang et al., 2006). 67 Interestingly, in fungi where KNL-2/M18BP1 proteins are absent, Myb domains can be found 
68 in HJURP/Scm3 proteins (Sanchez-Pulido et al., 2009), suggesting potential fusion of

69 multiple functions within a single polypeptide.

70 Here, we investigate CENP-A chromatin in C. elegans, which requires KNL-2/M18BP1

71 for its assembly but lacks an HJURP/Scm3 family member. C. elegans is holocentric, with

72 condensed mitotic chromosomes having two "stripes" of CENP-A chromatin-one per sister

73 chromatid-on geometrically opposite surfaces (Maddox et al., 2007; Melters et al., 2012).

74 Genomic approaches have localized CENP-A and KNL-2 to broad permissive domains in the

75 C. elegans genome that are transcriptionally inactive (Gassmann et al., 2012), although

76 restriction to specific sites has also been suggested (Steiner and Henikoff, 2014). We focused

77 on the unusually long amino-terminal tail (N-Tail) of $C$. elegans CENP-A, which, unlike the N-

78 termini of CENP-A from other species, is predicted to harbor a region with a-helical secondary

79 structure. Analysis of the divergent N-Tails of CENP-A family members have implicated them

80 in kinetochore assembly and epigenetic stability of centromeric chromatin (Fachinetti et al.,

81 2013; Folco et al., 2015; Ravi et al., 2010). Employing single copy, targeted transgene

82 insertion to replace endogenous CENP-A, we find that the $\mathrm{N}$-Tail of $C$. elegans CENP-A is

83 essential for CENP-A loading, and we link this essential function to a direct interaction

84 between the $\mathrm{N}$-Tail and the loading factor KNL-2/M18BP1. Interaction of the extended N-Tail

85 of $C$. elegans CENP-A to KNL-2/M18BP1 represents an evolutionary variation to

86 HJURP/Scm3-mediated targeting of the specialized histone fold of CENP-A to centromeres. 


\section{RESULTS}

88 The C. elegans CENP-A N-Tail has a Predicted Structured Region that is Essential for

The C. elegans CENP-A N-Tail is unusually long at 189 amino acids and, based on

91 computational analysis (performed using PSIPRED; http://bioinf.cs.ucl.ac.uk/psipred/), is

92 predicted to be $\alpha$-helical in the first 100 amino acids and unstructured afterwards (Fig. 1A).

93 The presence of a structured region in the $\mathrm{N}$-tail is unexpected as the CENP-A tail is often

94 short (e.g. in fission yeast or humans, where it is 20 and 39 aa, respectively) and, even in other species with extended CENP-A N-Tails-such as D. melanogaster (123 aa) or S. cerevisiae (130 aa)—are not predicted to have any secondary structure (Fig. 1A). mutants. In brief, the nucleotide sequence of the CENP-A $A^{\text {hcp-3 }}$ coding region was altered to maintain the native amino acid sequence while enabling selective RNAi-mediated depletion

102 of endogenous CENP-A ${ }^{\mathrm{HCP}-3}$; in addition, an N-terminal GFP tag was added to monitor 103 localization (Fig. S1). The wildtype, as well as two mutant transgenes $(\Delta 109$, which removes 104 the predicted structured region, and $\Delta 184$, which removes the majority of the $\mathrm{N}$-Tail), were 105 inserted in single copy at a fixed genomic location harboring a Mos transposon insertion (Fig.

106 1B; Fig. S1). The re-encoded gfp::CENP-A ${ }^{h c p-3}$ transgene fully rescued embryonic lethality 107 observed following depletion of endogenous CENP-A $\mathrm{A}^{\mathrm{HCP}-3}$ by RNAi as well as the lethality of 108 a deletion mutant ( $h c p-3(0 k 1892)$, referred to as $C E N P-A^{h c p-3} \Delta ;$ Fig 1C). By contrast, deletion 109 of the predicted structured region $(\Delta 109)$ and of the majority of the $\mathrm{N}$-Tail $(\Delta 184)$ resulted in 110 fully penetrant embryonic lethality (Fig. 1C). Immunoblotting with an antibody raised to the 111 unstructured linker (amino acids $105-183$ of the $\mathrm{N}$-Tail) indicated that the $\Delta 109$ mutant was 
112 expressed similarly to endogenous CENP-A ${ }^{\mathrm{HCP}-3}$ and the transgene-encoded WT

113 GFP::CENP-A ${ }^{\mathrm{HCP}-3}$ (Fig. 1D). Hence, the observed lethality is not because the $\Delta 109 \mathrm{~N}$-Tail

114 mutant is not expressed. We therefore conclude that the predicted structured region of the $\mathrm{N}$ -

115 Tail of CENP-A is essential for viability of C. elegans embryos.

116 The CENP-A ${ }^{H C P-3}$ N-Tail Deletion Mutant Exhibits a Kinetochore-Null Phenotype in One-

117 Cell Embryos

118 We next assessed the phenotype observed when endogenous CENP-A ${ }^{\mathrm{HCP}-3}$ was replaced by 119 the $\Delta 109 \mathrm{~N}-T$ ail mutant. We crossed an mCherry::H2b marker into strains harboring single120 copy transgenes expressing WT or $\triangle 109$ GFP::CENP-A ${ }^{\mathrm{HCP}-3}$, depleted endogenous CENP$121 \mathrm{~A}^{\mathrm{HCP}-3}$ by RNAi, and imaged one-cell embryos. As a control, we also depleted CENP-A ${ }^{\mathrm{HCP}-3}$ 122 in the absence of any transgene. Depletion of CENP-A resulted in the characteristic 123 kinetochore-null phenotype, with two clusters of chromatin-one from each pronucleus124 instead of a metaphase plate, and a failure of segregation (Fig. 2A; (Desai et al., 2003; 125 Oegema et al., 2001). This severe phenotype was fully rescued by transgene-encoded RNAi126 resistant WT GFP::CENP-A ${ }^{\mathrm{HCP}-3}$. By contrast, the observed phenotype for the $\Delta 109 \mathrm{~N}-\mathrm{Tail}$ 127 mutant was similar to that of removal of CENP-A ${ }^{\mathrm{HCP}-3}$ (Fig. 2A). Thus, deletion of the first 109 128 amino acids of the $\mathrm{N}$-Tail of CENP-A $\mathrm{A}^{\mathrm{HCP}-3}$ results in a chromosome segregation phenotype 129 that is equivalent to CENP-A ${ }^{\mathrm{HCP}-3}$ removal in the C. elegans embryo.

\section{The CENP-A ${ }^{H C P-3}$ N-Tail Deletion Mutant Does Not Accumulate on Chromatin and Fails}

Stable incorporation of CENP-A into chromatin in yeast and humans involves a region

133 of the histone fold, referred to as the CATD, which is specifically bound by the chaperone 134 Scm3/HJURP (Black et al., 2007; Cho and Harrison, 2011; Hu et al., 2011). In these species, 
135 the $\mathrm{N}$-tail is not essential for CENP-A centromere targeting, and alterations of the N-Tail do 136 not phenocopy loss of CENP-A (Chen et al., 2000; Fachinetti et al., 2013; Folco et al., 2015).

137 The similar phenotypes observed for CENP-A ${ }^{\mathrm{HCP}-3}$ removal and for the $\Delta 109 \mathrm{~N}$-Tail mutant of

138 C. elegans CENP-A suggested that the $\Delta 109 \mathrm{~N}$-Tail mutant, in contrast to the $\mathrm{N}$-Tail mutants 139 in other species, does not accumulate on centromeric chromatin. To test this idea, we imaged 140 WT and $\triangle 109$ GFP::CENP-A $\mathrm{ACP}^{\mathrm{HC}}$ in a strain co-expressing mCherry::H2b, and quantified the

141 GFP signal on metaphase chromosomes. In the presence of endogenous CENP-A ${ }^{\mathrm{HCP}-3}$, both

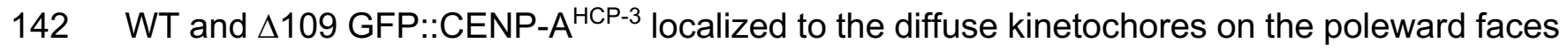

143 of the holocentric mitotic chromosomes (Fig. 2B) and quantification of fluorescence intensity

144 indicated equivalent localization of both (Fig. 2C). However, in the absence of endogenous

145 CENP-A ${ }^{\mathrm{HCP}-3}$, localization of $\triangle 109$ GFP::CENP-A ${ }^{\mathrm{HCP}-3}$ was greatly reduced relative to WT 146 GFP.:CENP-A ${ }^{\mathrm{HCP}-3}$ (Fig. 2B,C). Thus, $\triangle 109$ GFP::CENP-A ${ }^{\mathrm{HCP}-3}$ fails to localize to chromatin 147 on its own.

148 The absence of the $\Delta 109$ CENP-A ${ }^{\mathrm{HCP}-3}$ mutant in chromatin should result in a 149 kinetochore assembly defect. To confirm that this was indeed the case, we analyzed the 150 localization of an RNAi-resistant mCherry-fusion of $\mathrm{KNL}-1$, an outer kinetochore scaffold 151 protein (Desai et al., 2003; Espeut et al., 2012). We introduced the transgene expressing this 152 fusion into the strain expressing either WT or $\triangle 109$ GFP::CENP-A ${ }^{\mathrm{HCP}-3}$, depleted endogenous $153 \mathrm{KNL}-1$ and $\mathrm{CENP}-\mathrm{A}^{\mathrm{HCP}-3}$, and imaged and quantified the $\mathrm{KNL}-1:: \mathrm{mCherry}$ signal. This 154 analysis revealed loss of $\mathrm{KNL}-1:: \mathrm{mCherry}$ localization in the $\Delta 109$ GFP::CENP-A ${ }^{\mathrm{HCP}-3}$ mutant 155 was analogous to the CENP-A ${ }^{\mathrm{HCP}-3}$ depletion (Fig. 2D,E). Thus, the $\Delta 109$ CENP-A ${ }^{\text {HCP-3 }}$ 156 mutant does not form centromeric chromatin, resulting in a failure in kinetochore assembly.

157 The Failure of the CENP-A $A^{H C P-3}$ N-Tail Deletion Mutant to Accumulate on Chromatin is 
159 CENP-A ${ }^{\text {HCP-3 }}$ is essential for kinetochore assembly (Oegema et al., 2001). The severe 160 reduction of $\triangle 109$ CENP-A ${ }^{\mathrm{HCP}-3}$ on condensed chromatin could be either due to a defect in its 161 loading or a secondary consequence of its inability to support kinetochore assembly. To 162 distinguish between these possibilities, we prevented kinetochore assembly by depleting

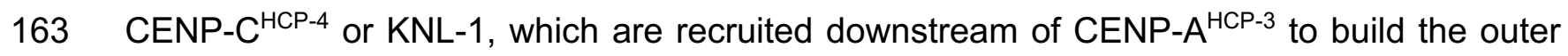
164 kinetochore (Desai et al., 2003; Oegema et al., 2001), and analyzed the effect on WT 165 GFP::CENP-A ${ }^{\text {HCP-3 }}$ chromatin accumulation; endogenous CENP-A ${ }^{\text {HCP-3 }}$ was also depleted. 166 As expected from prior work, both CENP-C ${ }^{\mathrm{HCP}-3}$ and $\mathrm{KNL}-1$ depletions resulted in a 167 kinetochore null phenotype. However, CENP-A ${ }^{\mathrm{HCP}-3}$ accumulation on chromatin was similar 168 to WT controls (Fig, 3A,B), indicating that a failure in kinetochore assembly is not the reason 169 for the loss of CENP-A ${ }^{\mathrm{HCP}-3}$ chromatin localization. Thus, the absence of $\Delta 109$ CENP-A ${ }^{\mathrm{HCP}-3}$ 170 on chromatin is likely due to a defect in its loading, rather than a consequence of its inability 171 to support kinetochore assembly. CENP-A ${ }^{\text {HCP-3 }}$ depletion, in addition to the kinetochore-null phenotype, also leads to 173 defects in condensation of the holocentric C. elegans chromosomes (Maddox et al., 2007; 174 Maddox et al., 2006). By contrast, preventing kinetochore formation by depletion of CENP$175 \mathrm{C}^{\text {HCP-4 }}$ does not result in a severe condensation defect (Maddox et al., 2006). We therefore 176 compared chromosome condensation in CENP-A ${ }^{\mathrm{HCP}-3}$ and CENP-C ${ }^{\mathrm{HCP}-4}$ depletion to that in 177 the $\Delta 109$ CENP-A ${ }^{\mathrm{HCP}-3}$ tail mutant. This analysis focused on sperm pronuclei as they are 178 formed prior to injection of the dsRNA employed to deplete endogenous CENP-A ${ }^{\mathrm{HCP}-3}$ and 179 are therefore free of potential meiotic defects (Maddox et al., 2006). Chromosome 180 condensation in the $\triangle 109$ CENP-A ${ }^{\mathrm{HCP}-3}$ mutant resembled that resulting from CENP-A ${ }^{\mathrm{HCP}-3}$ 181 depletion and not CENP-C $\mathrm{CHP}^{\mathrm{HC}}$ depletion, providing additional support that the $\Delta 109$ mutant 182 is compromised for its loading onto chromatin. Taken together, the results from these two 
183 distinct assays argue that the severe reduction of $\Delta 109$ mutant of CENP-A ${ }^{\mathrm{HCP}-3}$ on chromatin

184 is not due to an inability to support kinetochore assembly but due to a defect in its loading.

187 The above results implicate the predicted structured region of the N-Tail of C. elegans CENP-

$188 \mathrm{~A}^{\mathrm{HCP}-3}$ in its loading on chromatin. In species with Scm3/HJURP, a key step in the loading 189 reaction is the interaction of the Scm3/HJURP-CENP-A complex with the Mis18 complex, 190 which includes the Myb domain-containing protein KNL-2 (also known as Mis18BP1, based 191 on its association with Mis18a/ $\beta$ in human cells (French et al., 2017; Fujita et al., 2007; 192 Maddox et al., 2007; Pan et al., 2019; Wang et al., 2014); to date, a Mis18a/ $\beta$ homolog has 193 not been identified in C. elegans). In addition, Scm3/HJURP functions as a chaperone for 194 assembly of CENP-A nucleosomes (Dunleavy et al., 2009; Foltz et al., 2009; Pidoux et al., 195 2009; Shuaib et al., 2010; Williams et al., 2009).

196 To determine how the N-Tail of CENP-A ${ }^{\mathrm{HCP}-3}$ contributes to its loading, we tested if it 197 interacts with KNL-2. KNL-2 family proteins are characterized by a conserved Myb-like DNA 198 binding domain and a predicted folded N-terminal domain referred to as the SANTA domain 199 (Fig. 4A; (Maddox et al., 2007; Zhang et al., 2006); in addition, they possess an 200 acidic/aromatic tail at the C-terminus (Fig. S2A). Using yeast two-hybrid analysis, we 201 observed a robust interaction between a segment of the middle region of KNL-2 (residues 202267 to 470; predicted to be unstructured) and the predicted $\alpha$-helical region of the $\mathrm{N}$-Tail of 203 CENP-A ${ }^{\mathrm{HCP}-3}$; an interaction between $\mathrm{KNL}-2$ and CENP-A ${ }^{\mathrm{HCP}-3}$ was also reported in a large204 scale two-hybrid screen of proteins essential for C. elegans embryogenesis (Boxem et al., 205 2008). This interaction was not observed with full-length KNL-2 but, as no interaction has 206 been observed with this fusion, this may be a false negative due to the full-length protein not 
207 being properly expressed/folded in yeast. Importantly, an interaction between similar regions

208 of CENP-A $\mathrm{ACP}^{\mathrm{HC}}$ and KNL-2 was also observed for the C. briggsae proteins (Fig. 4B), despite

209 primary sequence divergence $\left(23.7 \%\right.$ identity/43.5 \% similarity for CENP-A ${ }^{\text {HCP-3 }} \mathrm{N}-\mathrm{Tail}$ \&

$21042.9 \%$ identity $/ 55.1 \%$ similarity for $\mathrm{KNL}-2$ middle region; Fig. S2B). The interaction was

211 species-specific, as the C. briggsae CENP-A ${ }^{\mathrm{HCP}-3} \mathrm{~N}-$ Tail did not interact with $C$. elegans KNL-

2122 middle region and vice versa (Fig. 4B).

213 To confirm the two-hybrid interaction, we performed pull-down assays with a purified

214 MBP-His6 fusion of the CENP-A ${ }^{\mathrm{HCP}-3} \mathrm{~N}-$ Tail immobilized on nickel agarose and in vitro-

215 translated MBP-KNL-2 fragments. We first screened a series of overlapping fragments of

$216 \mathrm{KNL}-2$ and found that, consistent with the yeast two-hybrid results, a fragment containing

217 residues 301-500 interacted with the $\mathrm{N}$-tail (Fig. 4C,E). We next analyzed a series of

218 truncated fragments in this region and found that a central region of 50 amino acids (376-

219 425) was essential for the interaction (Fig. 4D,E). However, this 50 amino acid region on its

220 own did not interact with the CENP-A ${ }^{\mathrm{HCP}-3} \mathrm{~N}-$ Tail (Fig. 4E), suggesting that residues on either

221 side are important for the observed interaction. We conclude that the predicted $\alpha$-helical

222 region of the $\mathrm{N}-\mathrm{Tail}$ of CENP-A $\mathrm{A}^{\mathrm{HCP}-3}$ that is important for chromatin loading in vivo interacts

223 directly with the CENP-A $\mathrm{ACP}^{\mathrm{HC}}$ loading factor $\mathrm{KNL}-2$ in vitro and that this interaction is

224 conserved in a related nematode species with a significantly diverged N-Tail sequence. 


\section{DISCUSSION}

226 Here, we investigated how CENP-A chromatin is assembled in the absence of a 227 HJURP/Scm3 family protein in C. elegans. We found that the unusually long N-tail of $C$.

228 elegans CENP-A, which contains a predicted $\alpha$-helical region, is required for CENP-A loading 229 onto chromatin. By contrast, the divergent N-Tails of CENP-A family members have been 230 proposed to contribute to kinetochore assembly and to epigenetic stability of centromeric 231 chromatin (Fachinetti et al., 2013; Folco et al., 2015; Ravi et al., 2010), but have not been 232 implicated in assembly of CENP-A chromatin. By comparing deletion of the predicted 233 structured region of the CENP-A N-Tail to two other perturbations that prevent kinetochore 234 assembly, we show that the absence of $\mathrm{N}$-Tail-mutant CENP-A $\mathrm{A}^{\mathrm{HCP}-3}$ on chromatin is due to a 235 failure in loading and not a consequence of defective kinetochore assembly. In addition, as 236 the N-Tail-mutant CENP-A ${ }^{\mathrm{HCP}-3}$ localizes normally in the presence of endogenous CENP$237 \mathrm{~A}^{\mathrm{HCP}-3}$, the absence of localization cannot be attributed to misfolding or inability to interact 238 with histone $\mathrm{H} 4$. Thus, the $\mathrm{N}$-Tail effectively acts as an intramolecular-targeting signal, 239 analogous to the CATD in HJURP/Scm3 containing species.

$240 \mathrm{HJURP} / \mathrm{Scm} 3$ has two roles-one is to act as a chaperone promoting assembly of

241 CENP-A nucleosomes, and the second is to target this assembly reaction to centromeric 242 chromatin through an interaction with centromere recognition factors (Ndc10 in budding 243 yeast, Mis18 in fission yeast, KNL-2 in C. elegans and plants, Mis18 complex in vertebrates).

244 Through two-hybrid and in vitro biochemical assays, we provide evidence that the C. elegans

245 CENP-A N-Tail possesses the latter activity-it interacts directly with the middle region of

$246 \mathrm{KNL}-2$ and this interaction is preserved in a species-specific manner in C. briggsae, despite

247 significant primary sequence divergence (especially in the $\mathrm{N}$-Tail sequence). A recent study 248 independently described a CENP-A ${ }^{\mathrm{HCP}-3} \mathrm{~N}$-tail $-\mathrm{KNL}-2$ interaction that is consistent with what 249 we report here (Prosée et al., 2020). Unfortunately, we have been unable to selectively 
250 mutate this interaction and assess the consequences in vivo-this will be important future

251 work. An obvious question emerging from our results is whether the N-tail of CENP-A ${ }^{\mathrm{HCP}-3}$

252 also exhibits chaperone activity, analogous to HJURP/Scm3. In preliminary work, we have

253 not observed an interaction between the N-Tail and the histone-fold of CENP-A ${ }^{\text {HCP-3 }}$ in two-

254 hybrid and in vitro binding assays, which would argue against presence of chaperone activity.

255 However, significant more effort needs to be placed on reconstitutions with purified

256 components to address whether these negative results are indeed due to absence of

257 chaperone activity. RNAi experiments have implicated the C. elegans ortholog of the histone-

258 binding WD40 domain chaperone RbAp46/48, LIN-53, in CENP-A chromatin assembly,

259 suggesting that it may work together with the $\mathrm{N}$-tail - KNL-2 interaction described here to

260 assemble centromeric chromatin (Lee et al., 2016).

261 In conclusion, we provide evidence for an evolutionary variation on CENP-A chromatin

262 assembly in which the N-tail of CENP-A has acquired part of the function of the specialized

263 chaperone/targeting factor HJURP/Scm3 and become essential for loading onto chromatin.

264 This represents a distinct solution from Drosophila, which also lacks HJURP/Scm3 but

265 appears to have convergently evolved an HJURP/Scm3-like chaperone called Cal1 (Chen et

266 al., 2014; Erhardt et al., 2008; Medina-Pritchard et al., 2020; Phansalkar et al., 2012).

267 Understanding how different species build CENP-A chromatin at restricted genomic locations

268 should provide insight into the general principles by which the epigenetic state of centromeric

269 chromatin is defined and propagated. 


\section{MATERIALS AND METHODS}

\section{C. elegans strains}

272

C. elegans strains (genotypes in Table S1) were maintained at $20^{\circ} \mathrm{C}$. Engineered

273 GFP::CENP-A ${ }^{\text {HCP-3 }}$ transgenes were cloned into PCFJ151 and injected into strain EG4322.

274 The KNL-1::mCherry transgene was cloned into pCFJ178 and injected into EG6700

275 (Frokjaer-Jensen et al., 2008). The amplified $h c p-3$ genomic locus was flanked on the 5 ' end

276 by 5'-GACGACGCTCCGAATCATTTGGGAG-3'and on the 3' end by 5'-

277 CTATTTGTCAAATAATAAAGATTCATTACTTGTAAATGAGAACATTTTATTTAA-3'. For the

278 GFP:: CENP-A ${ }^{\text {HCP-3 }}$ transgenes the GFP sequence was inserted following the start codon and 279 preceded by a GGRAGSGGRAGSGGRAGS linker. All exons were reencoded in CENP-A ${ }^{\text {hcp- }}$

$280{ }^{3}$ to allow RNAi-mediated depletion of endogenous CENP-A without affecting the introduced 281 transgene. Single copy insertion was confirmed by PCR. Transgenic strains were crossed 282 into various marker or deletion strains using standard genetic procedures.

\section{RNA-mediated interference (RNAi)}

284 Double-stranded RNAs were generated using oligos (Table S2) to amplify regions from N2 285 genomic DNA or CDNA. PCR reactions were used as templates for in vitro RNA production 286 (Ambion), and the RNA was purified using a MegaClear kit (Ambion). Eluted RNA from the 287 T3 and T7 reactions were mixed together, combined with $3 x$ soaking buffer $(32.7 \mathrm{mM}$ $288 \mathrm{Na}_{2} \mathrm{HPO}_{4}, 16.5 \mathrm{mM} \mathrm{KH}_{2} \mathrm{PO}_{4}, 6.3 \mathrm{mM} \mathrm{KCl}, 14.1 \mathrm{mM} \mathrm{NH}_{4} \mathrm{Cl}$ ), and annealed ( $68^{\circ} \mathrm{C}$ for $10 \mathrm{~min}$., $28937^{\circ} \mathrm{C}$ for $30 \mathrm{~min}$ ). dsRNA was injected into L3/L4 hermaphrodite worms $38-42$ hours prior to 290 imaging. For double depletions dsRNAs were mixed in equal amounts $(\geq 1-3 \mathrm{mg} / \mathrm{ml}$ for each 291 RNA). 


\section{Immunoblotting}

293 For immunoblotting a mixed population of worms growing at $20^{\circ} \mathrm{C}$ on an NGM+OP50 agar 294 plate were collected with M9+0.1\% TritonX-100, pelleted, and washed. Worms were vortexed

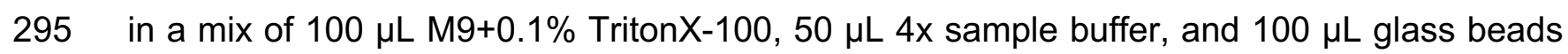

296 and boiled then vortexed and boiled again. Samples were run on an SDS-PAGE gel,

297 transferred to a PVDF membrane, probed with $1 \mu \mathrm{g} / \mathrm{ml}$ affinity-purified

298 anti-CENP-A ${ }^{\mathrm{HCP}-3}$ (rabbit; antigen was CENP-A ${ }^{\text {HCP-3 }}$ (105-183)::6xHis) and detected using an

299 HRP-conjugated secondary antibody (rabbit or mouse; GE Healthcare). For antibody 300 production CENP-A ${ }^{\text {HCP-3 }}(105-183):: 6$ xHis was expressed in E. coli, purified, and injected into 301 rabbits (Covance). Serum was affinity purified on a HiTrap NHS column to which CENP-A ${ }^{\text {HCP- }}$ $302{ }^{3}(105-183):: 6 x$ His was covalently coupled.

\section{Yeast Two Hybrid Screens}

304 Yeast two hybrid analysis was performed according to the manufacturer guidelines 305 (Matchmaker; Clontech Laboratories, Inc.). Genes of interest were cloned from wildtype (N2) 306 C. elegans or C. briggsae cDNA.

\section{Imaging and Quantification}

308 For all experiments images were acquired using an inverted Zeiss Axio Observer Z1 system 309 with a Yokogawa spinning-disk confocal head (CSU-X1), a 63x 1.4 NA Plan Apochromat 310 objective, and a QuantEM 512SC EMCCD camera (Photometrics). Environmental 311 temperatures during experimental acquisitions averaged $19^{\circ} \mathrm{C}$.

312 For live imaging of one-cell embryos, gravid hermaphrodite adult worms were 313 dissected into M9 buffer, embryos were manually transferred to $2 \%$ agarose pads, and 
314 overlaid with a coverslip. To monitor chromosome localizations a $5 \times 2 \mu \mathrm{m}$ z-series was

315 collected every $10-15$ s in one-cell embryos.

$316 \quad$ All images and movies were processed, scaled, and analyzed using ImageJ (Fiji), and

317 Photoshop (Adobe). Quantification of CENP-A ${ }^{\mathrm{HCP}-3}$ and KNL-1 kinetochore localization

318 during metaphase of one-cell embryos was performed on maximum intensity projections. A

319 rectangle was drawn around the fluorescence signal and average pixel intensity was

320 measured. The rectangle was expanded on all sides by a few pixels and the difference in

321 integrated intensity between the expanded rectangle and the original rectangle was used to

322 define the background intensity per pixel. Integrated fluorescence was then calculated for the

323 original rectangle after background subtraction (Moyle et al., 2014).

\section{Protein Purification}

325 CENP-A ${ }^{H C P-3}$ (1-109)-MBP-6xHis was cloned into pET21a. HCP-3(1-109)-MBP-6xHis and

326 MBP::6xHis were expressed in BL21(DE3). E. coli cultures were grown to OD 600 0.6-0.8 and

327 induced with $0.1 \mathrm{mM} \mathrm{IPTG}$ for 6 hours at $20^{\circ} \mathrm{C}$. Induced BL21(DE3) cells were lysed in Lysis

328 Buffer (20 mM Tris [pH 7.5], $300 \mathrm{mM} \mathrm{NaCl}, 20 \mathrm{mM}$ imidazole, $8 \mathrm{mM}$-mercaptoethanol

$329[\mathrm{BME}]$ ) and clarified at $40,000 \mathrm{~g}$ for $45 \mathrm{~min}$ at $4^{\circ} \mathrm{C}$. Ni-NTA agarose (Qiagen) was incubated

330 with clarified lysates for $45 \mathrm{~min}$, washed with Wash Buffer (20 mM Tris [pH 7.5], $300 \mathrm{mM}$

$331 \mathrm{NaCl}, 50 \mathrm{mM}$ imidazole, $8 \mathrm{mM} \mathrm{BME}$ ), and eluted with $20 \mathrm{mM}$ Tris [pH 7.5], $300 \mathrm{mM} \mathrm{NaCl}$,

$332300 \mathrm{mM}$ imidazole, $8 \mathrm{mM}$ BME. The eluted protein was fractionated using a Superose10 gel

333 filtration column (GE Healthcare). Protein concentrations were determined using a NanoDrop

3341000 spectrophotometer (Thermo Scientific). 
336 KNL-2-MBP fragments were ${ }^{[35]}$ labeled using TnT® Quick Coupled

337 Transcription/Translation System (Promega). $10 \mu \mathrm{l}$ of the in vitro translation lysate was

338 incubated for $1 \mathrm{hr}$ at $4^{\circ} \mathrm{C}$ with $50 \mu \mathrm{g}$ CENP-A $\mathrm{HCP}-3^{\mathrm{H}}(1-109)-\mathrm{MBP}-\mathrm{His}$ (in $20 \mathrm{mM}$ Tris [pH7.5], 300

$339 \mathrm{mM} \mathrm{Nacl}, 0.05 \% \mathrm{NP} 40,10 \mathrm{mM}$ Imidazole) in a final volume of $50 \mu \mathrm{l}$, mixed with $25 \mu \mathrm{l}$ of a

$340 \quad$ 1:1 nickel agarose slurry equilibrated with the binding buffer for an additional hour at $4^{\circ} \mathrm{C}$.

341 Beads were washed three times with binding buffer, eluted using sample buffer and the

342 elution analyzed by SDS-PAGE and autoradiography.

\section{ACKNOWLEDGMENTS}

344 This work was supported by an NIH grant (GM074215) to A.D., a German Research

345 Foundation (DFG) grant (GR 3859/1-1) to C.D.G., a NSF Graduate Research Fellowship to

346 J.H., and an EMBO Fellowship (ALTF 251-2012) to A.G-G. A.D., K.O. and A.K.S. received

347 salary and other support from Ludwig Cancer Research. 
349 Figure 1. The extended $\mathrm{N}-$ Tail of $C$. elegans CENP-A ${ }^{\mathrm{HCP}-3}$ contains a predicted 350 structured region that is essential for viability.

351 (A) Secondary structure predictions of CENP-A from different model organism species. 352 Secondary structure predictions were generated using PsiPred. Predicted alpha helical 353 segments are indicated as boxes. The histone fold domain (HFD) is marked in grey.

354 (B) Schematic of RNAi-resistant gfp::CENP-A $A^{h c p-3}$ single copy transgene insertions on 355 Chromosome II. The three variants of CENP-A ${ }^{\mathrm{HCP}-3}$ expressed from single copy transgene 356 insertions are indicated below.

357 (C) Embryo viability analysis for the indicated conditions. $N$ refers to the number of worms 358 and $n$ to the total number of embryos scored. Error bars are the SEM.

359 (D) Anti-CENP-A ${ }^{\mathrm{HCP}-3}$ immunoblot performed using an antibody raised to the linker region 360 (aa105-183) showing expression levels of WT GFP-CENP-A ${ }^{\text {HCP-3 }}$ and the $\Delta 109$ N-Tail 361 truncation mutant in the presence and absence of endogenous CENP-A $\mathrm{A}^{\mathrm{HCP}-3}(\Delta$ indicates 362 homozygous CENP- $A^{h c p-3}$ deletion mutant; (RNAi) indicates CENP-A $\left.{ }^{h c p-3}(R N A i)\right)$. Asterisk (*) 363 marks a background band that serves as a loading control.

364 Figure 2. Deletion of the predicted $\alpha$-helical region of the CENP-A ${ }^{\mathrm{HCP}-3} \mathrm{~N}-T$ ail results in 365 a kinetochore-null phenotype and failure to accumulate on mitotic chromatin.

366 (A) mCherry::H2b images from timelapse sequences for the indicated conditions in 367 metaphase and anaphase-stage one-cell embryos. Similar results were obtained in at least 36810 embryos per condition. Scale bar, $5 \mu \mathrm{m}$.

369 (B) Images of WT and $\triangle 109$ GFP::CENP- ${ }^{H C P-3}$ in metaphase stage embryos expressing $370 \mathrm{mCherry}-\mathrm{H} 2 \mathrm{~b}$ in the presence (left set of pane/s) or absence (right set of panels) of 371 endogenous CENP-A ${ }^{\mathrm{HCP}-3}$. Scale bar, $2.5 \mu \mathrm{m}$. 
372 (C) Quantification of integrated chromosomal GFP intensity in metaphase stage embryos for

373 the indicated conditions. t-tests were used to assess if indicated pair-wise comparisons were

374 significantly different. Error bars are the SD.

375 (D) Images of $\mathrm{KNL}-1:: \mathrm{mCherry}$, expressed from an integrated single copy RNAi-resistant 376 transgene, in metaphase stage one-cell embryos for the indicated conditions; note that

377 endogenous KNL-1 was depleted in all cases. Scale bar, $5 \mu \mathrm{m}$.

378 (E) Quantification of integrated KNL-1::mCherry kinetochore intensity in metaphase stage 379 embryos for the indicated conditions. Error bars are the SD.

380 Figure 3: Inability of $\Delta 109$ CENP-A ${ }^{\mathrm{HCP}-3}$ to accumulate on chromatin is not due to failure 381 of kinetochore assembly.

382 (A) Images of WT GFP::CENP-A ${ }^{\mathrm{HCP}-3}$ in metaphase stage embryos also expressing 383 mCherry::H2b that were depleted of endogenous CENP-A ${ }^{\mathrm{HCP}-3}$ and $\mathrm{KNL}-1$ (top) or CENP$384 \mathrm{C}^{\mathrm{HCP}-4}$ (bottom). Scale bar, $5 \mu \mathrm{m}$.

385 (B) Quantification of integrated chromosomal WT GFP::CENP-A ${ }^{\text {HCP-3 }}$ intensity in metaphase 386 stage embryos for the indicated conditions. The CENP- $A^{h c p-3}(R N A i)$ alone value is the same 387 as in Fig. 2C. Error bars are the SD. t-tests were employed to assess statistical significance 388 of indicated pair-wise comparisons.

389 (C) Images of mCherry::H2b in sperm pronuclei from timelapse sequences for the indicated 390 conditions. Times are in seconds after nuclear envelope breakdown (NEBD). Similar results 391 were observed in at least 10 embryos filmed per condition. Scale bar, $5 \mu \mathrm{m}$.

392 Figure 4. The N-Tail of CENP-A ${ }^{\mathrm{HCP}-3}$ interacts with an unstructured middle region of 393

KNL-2. 
394 (A) Domain structure of KNL-2. The presence of the SANTA domain (PF09133) and the Myb 395 domain (also known as the SANT domain; PF00249) is conserved among the KNL-2/M18BP1 396 protein family. No secondary structure elements are predicted in the middle region of KNL-2. 397 (B) Yeast two-hybrid analysis of CENP-A ${ }^{\mathrm{HCP}-3} \mathrm{~N}-\mathrm{T}$ ail and KNL-2. The bait CENP-A ${ }^{\mathrm{HCP}-3} \mathrm{~N}-$ 398 Tail fusions are listed on top and the prey KNL-2 fusions are listed on the left.

399 (C)-(E) Biochemical analysis of the CENP-A ${ }^{\mathrm{HCP}-3}-\mathrm{KNL}-2$ interaction. Nickel-immobilized 400 recombinant CENP-A ${ }^{\mathrm{HCP}-3}(1-109)-\mathrm{MBP}^{-H i s_{6}}$ was used to pull-down indicated reticulocyte 401 lysate-expressed $S^{35}$-labeled MBP-KNL-2 fragments. In (C), $S^{35}$-autoradiogram (top) shows 402 Input (I) and bead-bound (B) KNL-2 fragments; Coomassie staining (bottom) shows input 403 lysate and CENP-A ${ }^{\mathrm{HCP}-3}(1-109)-\mathrm{MBP}_{-} \mathrm{His}_{6}$ bait. In $(D)$, fragments of the 301-500 amino acid 404 region of $\mathrm{KNL}-2$ tested for binding to CENP-A $\mathrm{ACP}^{\mathrm{HC}}(1-109)$ are schematized on the left. $\mathrm{S}^{35}$ 405 autoradiogram (top) shows reticulocyte lysate-expressed MBP-KNL-2 fragments; $\mathrm{S}^{35}$ 406 autoradiogram (middle) shows bound KNL-2 fragments; Coomassie staining (bottom) shows 407 CENP-A ${ }^{\mathrm{HCP}-3} \mathrm{~N}-\mathrm{T}$ ail bait. In $(E)$, indicated KNL-2 fragments were tested for binding to control 408 (MBP-His 6 ) and CENP-A ${ }^{\mathrm{HCP}-3}(1-109)-\mathrm{MBP}-\mathrm{His}_{6}$ baits. $\mathrm{S}^{35}$-autoradiogram (top) shows input 409 and bound fragments; Coomassie staining (bottom) shows input lysates and baits. 
411 Supplementary Figure 1. Design of the RNAi-resistant transgene used to replace endogenous CENP-A $\mathrm{A}^{\mathrm{HCP}-3}$.

413 Schematic of the gfp::hcp-3 RNAi-resistant single copy transgene. All of the exons of $h c p-3$

414 were re-encoded to preserve amino acid sequence but make the nucleotide sequence

415 resistant to a dsRNA generated using the hcp-3 cDNA. The intron sequences (indicated in

416 black) were not altered.

417 Supplementary Figure 2. Sequence alignment of KNL-2 protein family domains \& C.

418 elegans/C. briggsae CENP-A N-tail predicted $\alpha$-helical regions.

419 (A) Alignment of KNL-2/M18BP1 domains from the following species: Ce, Caenorhabditis 420 elegans; Hs, Homo sapiens; Gg, Gallus gallus; Xt, Xenopus tropicalis; Dr, Danio rerio; Bm,

421 Brugia malayi; Sp, Strongylocentrotus purpuratus; $\mathrm{Ci}$, Ciona intestinalis. Dark blue lines

422 indicate identical residues and lighter blue lines indicate similar residues among different

423 species. Red and magenta-colored residues in the bottom panel of the C-terminal end 424 highlight acidic and aromatic residues, respectively. Sequences alignments were performed 425 using Clustal Omega.

426 (B) Alignment of $C$. elegans and $C$. briggsae predicted $\mathrm{N}$-tail $\alpha$-helical region and of the 427 interacting middle region from KNL-2. 
Table S1. C. elegans strains used in this study

\begin{tabular}{|c|c|}
\hline Strain Number & Genotype \\
\hline N2 & Ancestral \\
\hline OD56 & $\begin{array}{l}\text { unc-119(ed3)III; ItIs37 [pAA64; Ppie- } \\
\text { 1::mCherry::his-58; unc-119 (+)]IV }\end{array}$ \\
\hline OD704 & $\begin{array}{l}\text { unc-119(ed3) III; ItSi396[pOD1368; gfp::hcp-3 } \\
\text { reencoded; cb unc-119 (+)]ll }\end{array}$ \\
\hline OD1290 & 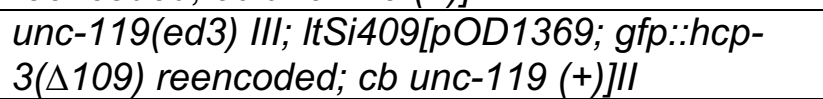 \\
\hline OD1283 & $\begin{array}{l}\text { unc-119(ed3) III; ItSi406[pOD1372; gfp::hcp- } \\
\text { 3( } \Delta 184) \text { reencoded); cb unc-119 (+)]ll }\end{array}$ \\
\hline OD1271 & $\begin{array}{l}\text { unc-119(ed3) III; ItSi400[pOD1366; knl-1 } \\
\text { reencoded::mCherry; cb unc-119 (+)]IV }\end{array}$ \\
\hline OD2450 & $\begin{array}{l}\text { unc-119(ed3) III; ItSi396[pOD1368; gfp::hcp-3 } \\
\text { reencoded; cb unc-119 (+)]II; ItIs37 [pAA64; } \\
\text { Ppie-1::mCherry::his-58; unc-119 (+)]IV }\end{array}$ \\
\hline OD1292 & $\begin{array}{l}\text { unc-119(ed3) III; ItSi409[pOD1369; gfp::hcp- } \\
\text { 3( } \Delta 109) \text { reencoded; cb unc-119 (+)]Il;/It/s37 } \\
\text { [pAA64; Ppie-1::mCherry::his-58; unc-119 } \\
(+)] I V\end{array}$ \\
\hline OD2451 & $\begin{array}{l}\text { unc-119(ed3) III; ItSi396[pOD1368; gfp::hcp-3 } \\
\text { reencoded; cb unc-119 (+)]II; ItSi400[pOD1366; } \\
\text { knl-1 reencoded::mCherry; cb unc-119 (+)]IV }\end{array}$ \\
\hline OD1291 & $\begin{array}{l}\text { unc-119(ed3) III; ItSi409[pOD1369; gfp::hcp-3 } \\
\text { reencoded(Mutant 110-288); cb unc-119 (+)]ll; } \\
\text { ItSi400[pOD1366; knl-1reencoded::mCherry; cb } \\
\text { unc-119 (+)]IV }\end{array}$ \\
\hline OD785 & $\begin{array}{l}\text { unc-119(ed3) III; ItSi396[pOD1368; gfp::hcp-3 } \\
\text { reencoded; cb unc-119 (+)]II; hcp-3(ok1892) III }\end{array}$ \\
\hline
\end{tabular}


bioRxiv preprint doi: https://doi.org/10.1101/2020.12.28.424576; this version posted December 28, 2020. The copyright holder for this preprint (which was not certified by peer review) is the author/funder, who has granted bioRxiv a license to display the preprint in perpetuity. It is made available under aCC-BY-NC-ND 4.0 International license.

\section{Table S2. Oligos and templates used for dsRNA production}

$\begin{array}{llll}\text { Gene } & \text { Oligonucleotide } \mathbf{1}\left(\mathbf{5}^{\prime} \rightarrow \mathbf{3}^{\prime}\right) & \text { Oligonucleotide } \mathbf{2}\left(\mathbf{5}^{\prime} \rightarrow \mathbf{3}^{\prime}\right) & \text { Template } \\ \text { hcp-3 (F58A4.3) } & \text { 5'-AATTAACCCTCACTAAAGGACACCC } & \text { 5'-TAATACGACTCACTATAGGCGAAGGC } & \text { N2 cDNA } \\ & \text { CAATTATTGAGGAATCGCCGAGC-3' } & \text { AGAGACGTCTGTATAACTGAATATCC-3' } & \\ \text { hcp-4 (T03F1.9) } & \text { 5'-AATTAACCCTCACTAAAGGCACTGT } & \text { 5'-TAATACGACTCACTATAGGGATT } & \text { N2 cDNA } \\ & \text { GGCTGAAGATGCTCCTGAAGAAC-3' } & \text { CGTGGCGGCGTTTGAACCACC-3' } & \\ \text { knl-1 (C02F5.1) } & \text { 5'-AATTAACCCTCACTAAAGGAA } & \text { 5'-TAATACGACTCACTATAGGTT } & \text { N2 cDNA } \\ & \text { TCTCGAATCACCGAAATGTC-3' } & \text { CACAAACTTGGAAGCCGCTG-3' } & \end{array}$


References:

Allshire, R.C., and G.H. Karpen. 2008. Epigenetic regulation of centromeric chromatin: old dogs, new tricks? Nat Rev Genet. 9:923-937.

Barnhart, M.C., P.H. Kuich, M.E. Stellfox, J.A. Ward, E.A. Bassett, B.E. Black, and D.R. Foltz. 2011. HJURP is a CENP-A chromatin assembly factor sufficient to form a functional de novo kinetochore. J Cell Biol. 194:229-243.

Black, B.E., D.R. Foltz, S. Chakravarthy, K. Luger, V.L. Woods, Jr., and D.W. Cleveland. 2004. Structural determinants for generating centromeric chromatin. Nature. 430:578-582.

Black, B.E., L.E. Jansen, P.S. Maddox, D.R. Foltz, A.B. Desai, J.V. Shah, and D.W. Cleveland. 2007. Centromere identity maintained by nucleosomes assembled with histone $\mathrm{H} 3$ containing the CENP-A targeting domain. Mol Cell. 25:309-322.

Boxem, M., Z. Maliga, N. Klitgord, N. Li, I. Lemmens, M. Mana, L. de Lichtervelde, J.D. Mul, D. van de Peut, M. Devos, N. Simonis, M.A. Yildirim, M. Cokol, H.L. Kao, A.S. de Smet, H. Wang, A.L. Schlaitz, T. Hao, S. Milstein, C. Fan, M. Tipsword, K. Drew, M. Galli, K. Rhrissorrakrai, D. Drechsel, D. Koller, F.P. Roth, L.M. lakoucheva, A.K. Dunker, R. Bonneau, K.C. Gunsalus, D.E. Hill, F. Piano, J. Tavernier, S. van den Heuvel, A.A. Hyman, and M. Vidal. 2008. A protein domain-based interactome network for C. elegans early embryogenesis. Cell. 134:534-545.

Chen, C.C., M.L. Dechassa, E. Bettini, M.B. Ledoux, C. Belisario, P. Heun, K. Luger, and B.G. Mellone. 2014. CAL1 is the Drosophila CENP-A assembly factor. J Cell Biol. 204:313-329.

Chen, Y., R.E. Baker, K.C. Keith, K. Harris, S. Stoler, and M. Fitzgerald-Hayes. 2000. The N terminus of the centromere $\mathrm{H} 3$-like protein Cse4p performs an essential function distinct from that of the histone fold domain. Mol Cell Biol. 20:7037-7048.

Cho, U.S., and S.C. Harrison. 2011. Recognition of the centromere-specific histone Cse4 by the chaperone Scm3. Proc Natl Acad Sci U S A. 108:9367-9371.

Desai, A., S. Rybina, T. Muller-Reichert, A. Shevchenko, A. Shevchenko, A. Hyman, and K. Oegema. 2003. KNL-1 directs assembly of the microtubule-binding interface of the kinetochore in C. elegans. Genes Dev. 17:2421-2435.

Dunleavy, E.M., D. Roche, H. Tagami, N. Lacoste, D. Ray-Gallet, Y. Nakamura, Y. Daigo, Y. Nakatani, and G. Almouzni-Pettinotti. 2009. HJURP is a cell-cycle-dependent maintenance and deposition factor of CENP-A at centromeres. Cell. 137:485-497.

Erhardt, S., B.G. Mellone, C.M. Betts, W. Zhang, G.H. Karpen, and A.F. Straight. 2008. Genomewide analysis reveals a cell cycle-dependent mechanism controlling centromere propagation. J Cell Biol. 183:805-818.

Espeut, J., D.K. Cheerambathur, L. Krenning, K. Oegema, and A. Desai. 2012. Microtubule binding by KNL-1 contributes to spindle checkpoint silencing at the kinetochore. $J$ Cell Biol. 196:469-482.

Fachinetti, D., H.D. Folco, Y. Nechemia-Arbely, L.P. Valente, K. Nguyen, A.J. Wong, Q. Zhu, A.J. Holland, A. Desai, L.E. Jansen, and D.W. Cleveland. 2013. A two-step mechanism for epigenetic specification of centromere identity and function. Nat Cell Biol. 15:1056-1066.

Folco, H.D., C.S. Campbell, K.M. May, C.A. Espinoza, K. Oegema, K.G. Hardwick, S.I.S. Grewal, and A. Desai. 2015. The CENP-A N-tail confers epigenetic stability to centromeres via the CENP-T branch of the CCAN in fission yeast. Curr Biol. 25:348-356.

Foltz, D.R., L.E. Jansen, A.O. Bailey, J.R. Yates, 3rd, E.A. Bassett, S. Wood, B.E. Black, and D.W. Cleveland. 2009. Centromere-specific assembly of CENP-a nucleosomes is mediated by HJURP. Cell. 137:472-484.

French, B.T., and A.F. Straight. 2019. CDK phosphorylation of Xenopus laevis M18BP1 promotes its metaphase centromere localization. EMBO J. 38. 
French, B.T., F.G. Westhorpe, C. Limouse, and A.F. Straight. 2017. Xenopus laevis M18BP1 Directly Binds Existing CENP-A Nucleosomes to Promote Centromeric Chromatin Assembly. Dev Cell. 42:190-199 e110.

Frokjaer-Jensen, C., M.W. Davis, C.E. Hopkins, B.J. Newman, J.M. Thummel, S.P. Olesen, M. Grunnet, and E.M. Jorgensen. 2008. Single-copy insertion of transgenes in Caenorhabditis elegans. Nat Genet. 40:1375-1383.

Fujita, Y., T. Hayashi, T. Kiyomitsu, Y. Toyoda, A. Kokubu, C. Obuse, and M. Yanagida. 2007. Priming of centromere for CENP-A recruitment by human hMis18alpha, hMis18beta, and M18BP1. Dev Cell. 12:17-30.

Gassmann, R., A. Rechtsteiner, K.W. Yuen, A. Muroyama, T. Egelhofer, L. Gaydos, F. Barron, P. Maddox, A. Essex, J. Monen, S. Ercan, J.D. Lieb, K. Oegema, S. Strome, and A. Desai. 2012. An inverse relationship to germline transcription defines centromeric chromatin in C. elegans. Nature. 484:534-537.

Hayashi, T., Y. Fujita, O. Iwasaki, Y. Adachi, K. Takahashi, and M. Yanagida. 2004. Mis16 and Mis 18 are required for CENP-A loading and histone deacetylation at centromeres. Cell. 118:715-729.

Hori, T., W.H. Shang, M. Hara, M. Ariyoshi, Y. Arimura, R. Fujita, H. Kurumizaka, and T. Fukagawa. 2017. Association of M18BP1/KNL2 with CENP-A Nucleosome Is Essential for Centromere Formation in Non-mammalian Vertebrates. Dev Cell. 42:181-189 e183.

Hu, H., Y. Liu, M. Wang, J. Fang, H. Huang, N. Yang, Y. Li, J. Wang, X. Yao, Y. Shi, G. Li, and R.M. Xu. 2011. Structure of a CENP-A-histone H4 heterodimer in complex with chaperone HJURP. Genes Dev. 25:901-906.

Jansen, L.E., B.E. Black, D.R. Foltz, and D.W. Cleveland. 2007. Propagation of centromeric chromatin requires exit from mitosis. J Cell Biol. 176:795-805.

Kato, H., J. Jiang, B.R. Zhou, M. Rozendaal, H. Feng, R. Ghirlando, T.S. Xiao, A.F. Straight, and Y. Bai. 2013. A conserved mechanism for centromeric nucleosome recognition by centromere protein CENP-C. Science. 340:1110-1113.

Kixmoeller, K., P.K. Allu, and B.E. Black. 2020. The centromere comes into focus: from CENP-A nucleosomes to kinetochore connections with the spindle. Open Biol. 10:200051.

Lee, B.C., Z. Lin, and K.W. Yuen. 2016. RbAp46/48(LIN-53) Is Required for Holocentromere Assembly in Caenorhabditis elegans. Cell Rep. 14:1819-1828.

Lermontova, I., M. Kuhlmann, S. Friedel, T. Rutten, S. Heckmann, M. Sandmann, D. Demidov, V. Schubert, and I. Schubert. 2013. Arabidopsis kinetochore null2 is an upstream component for centromeric histone H3 variant cenH3 deposition at centromeres. Plant Cell. 25:33893404.

Maddox, P.S., F. Hyndman, J. Monen, K. Oegema, and A. Desai. 2007. Functional genomics identifies a Myb domain-containing protein family required for assembly of CENP-A chromatin. J Cell Biol. 176:757-763.

Maddox, P.S., N. Portier, A. Desai, and K. Oegema. 2006. Molecular analysis of mitotic chromosome condensation using a quantitative time-resolved fluorescence microscopy assay. Proc Natl Acad Sci U S A. 103:15097-15102.

McKinley, K.L., and I.M. Cheeseman. 2016. The molecular basis for centromere identity and function. Nat Rev Mol Cell Biol. 17:16-29.

Medina-Pritchard, B., V. Lazou, J. Zou, O. Byron, M.A. Abad, J. Rappsilber, P. Heun, and A.A. Jeyaprakash. 2020. Structural basis for centromere maintenance by Drosophila CENP-A chaperone CAL1. EMBO J. 39:e103234.

Mellone, B.G., K.J. Grive, V. Shteyn, S.R. Bowers, I. Oderberg, and G.H. Karpen. 2011. Assembly of Drosophila centromeric chromatin proteins during mitosis. PLoS Genet. 7:e1002068.

Melters, D.P., L.V. Paliulis, I.F. Korf, and S.W. Chan. 2012. Holocentric chromosomes: convergent evolution, meiotic adaptations, and genomic analysis. Chromosome Res. 20:579-593. 
Mitra, S., B. Srinivasan, and L.E.T. Jansen. 2020. Stable inheritance of CENP-A chromatin: Inner strength versus dynamic control. J Cell Biol. 219.

Moree, B., C.B. Meyer, C.J. Fuller, and A.F. Straight. 2011. CENP-C recruits M18BP1 to centromeres to promote CENP-A chromatin assembly. J Cell Biol. 194:855-871.

Moyle, M.W., T. Kim, N. Hattersley, J. Espeut, D.K. Cheerambathur, K. Oegema, and A. Desai. 2014. A Bub1-Mad1 interaction targets the Mad1-Mad2 complex to unattached kinetochores to initiate the spindle checkpoint. J Cell Biol. 204:647-657.

Musacchio, A., and A. Desai. 2017. A Molecular View of Kinetochore Assembly and Function. Biology (Basel). 6.

Oegema, K., A. Desai, S. Rybina, M. Kirkham, and A.A. Hyman. 2001. Functional analysis of kinetochore assembly in Caenorhabditis elegans. J Cell Biol. 153:1209-1226.

Ohzeki, J., J.H. Bergmann, N. Kouprina, V.N. Noskov, M. Nakano, H. Kimura, W.C. Earnshaw, V. Larionov, and H. Masumoto. 2012. Breaking the HAC Barrier: histone H3K9 acetyl/methyl balance regulates CENP-A assembly. EMBO J. 31:2391-2402.

Pan, D., K. Walstein, A. Take, D. Bier, N. Kaiser, and A. Musacchio. 2019. Mechanism of centromere recruitment of the CENP-A chaperone HJURP and its implications for centromere licensing. Nat Commun. 10:4046.

Phansalkar, R., P. Lapierre, and B.G. Mellone. 2012. Evolutionary insights into the role of the essential centromere protein CAL1 in Drosophila. Chromosome Res. 20:493-504.

Pidoux, A.L., E.S. Choi, J.K. Abbott, X. Liu, A. Kagansky, A.G. Castillo, G.L. Hamilton, W. Richardson, J. Rappsilber, X. He, and R.C. Allshire. 2009. Fission yeast Scm3: A CENPA receptor required for integrity of subkinetochore chromatin. Mol Cell. 33:299-311.

Prosée, R.F., J.M. Wenda, C. Gabus, K. Delaney, F. Schwager, M. Gotta, and F.A. Steiner. 2020. Trans-generational inheritance of centromere identity requires the CENP-A N-terminal tail in the C. elegans maternal germ line. bioRxiv.

Ravi, M., P.N. Kwong, R.M. Menorca, J.T. Valencia, J.S. Ramahi, J.L. Stewart, R.K. Tran, V. Sundaresan, L. Comai, and S.W. Chan. 2010. The rapidly evolving centromere-specific histone has stringent functional requirements in Arabidopsis thaliana. Genetics. 186:461471.

Sanchez-Pulido, L., A.L. Pidoux, C.P. Ponting, and R.C. Allshire. 2009. Common ancestry of the CENP-A chaperones Scm3 and HJURP. Cell. 137:1173-1174.

Shuaib, M., K. Ouararhni, S. Dimitrov, and A. Hamiche. 2010. HJURP binds CENP-A via a highly conserved N-terminal domain and mediates its deposition at centromeres. Proc Natl Acad Sci U S A. 107:1349-1354.

Steiner, F.A., and S. Henikoff. 2014. Holocentromeres are dispersed point centromeres localized at transcription factor hotspots. Elife. 3:e02025.

Wang, J., X. Liu, Z. Dou, L. Chen, H. Jiang, C. Fu, G. Fu, D. Liu, J. Zhang, T. Zhu, J. Fang, J. Zang, J. Cheng, M. Teng, X. Ding, and X. Yao. 2014. Mitotic regulator Mis18beta interacts with and specifies the centromeric assembly of molecular chaperone holliday junction recognition protein (HJURP). J Biol Chem. 289:8326-8336.

Williams, J.S., T. Hayashi, M. Yanagida, and P. Russell. 2009. Fission yeast Scm3 mediates stable assembly of Cnp1/CENP-A into centromeric chromatin. Mol Cell. 33:287-298.

Zhang, D., C.J. Martyniuk, and V.L. Trudeau. 2006. SANTA domain: a novel conserved protein module in Eukaryota with potential involvement in chromatin regulation. Bioinformatics. 22:2459-2462. 
A

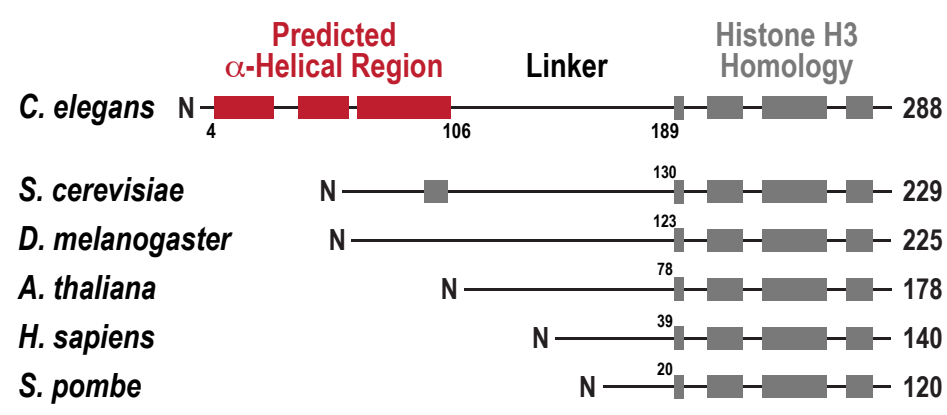

B
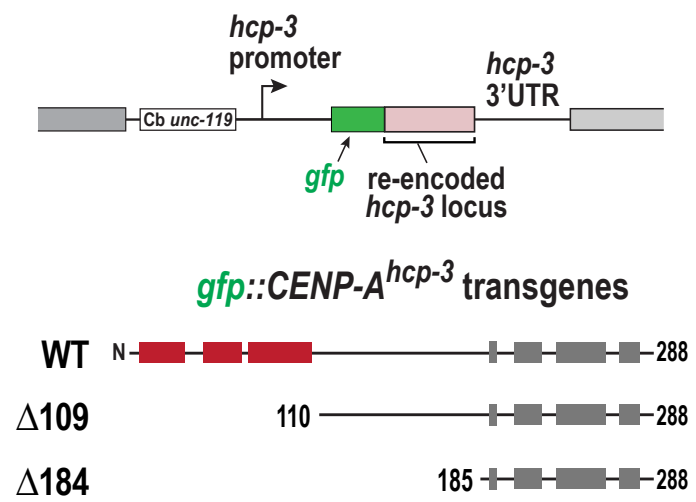

C Embryonic Viability (\%)

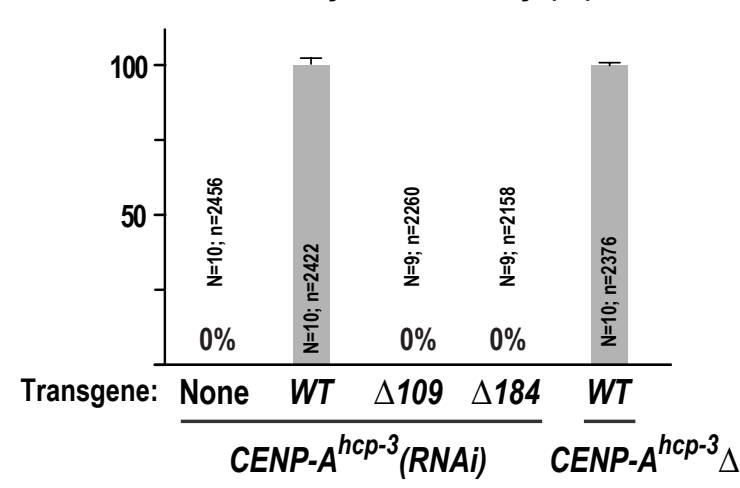

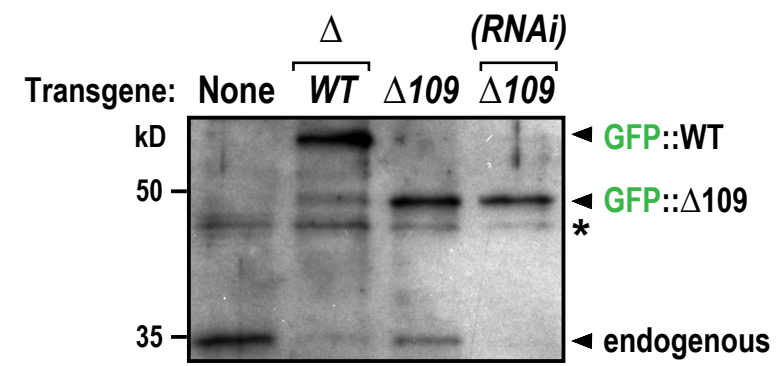

IB: $\alpha$-Linker Ab (aa 105-183) 
A

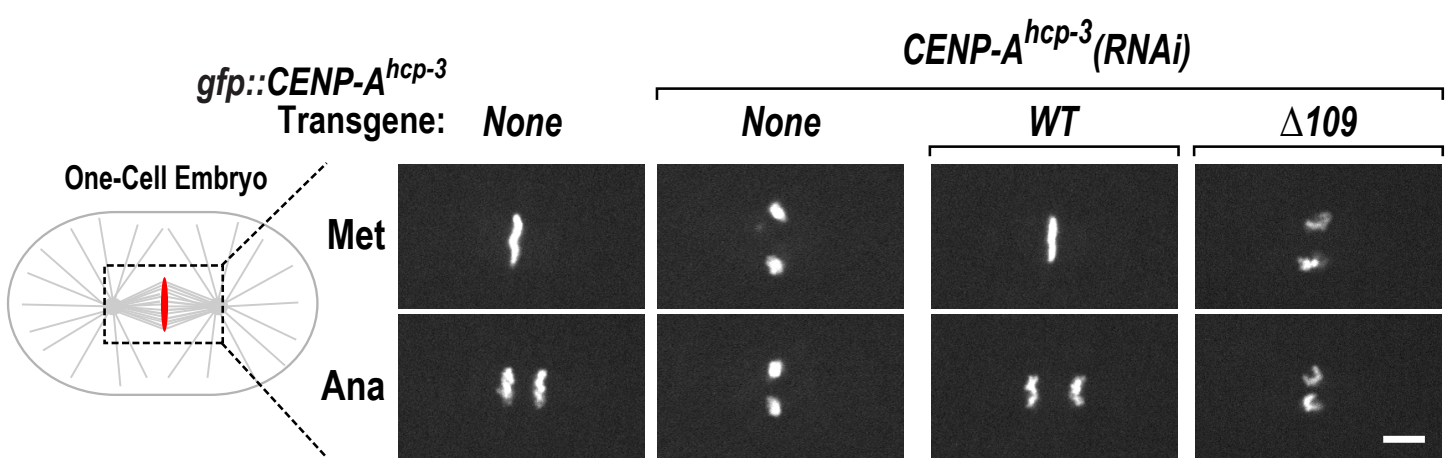

mCherry::H2b

B

Endogenous CENP-A ${ }^{\text {HCP-3 }}$ Present

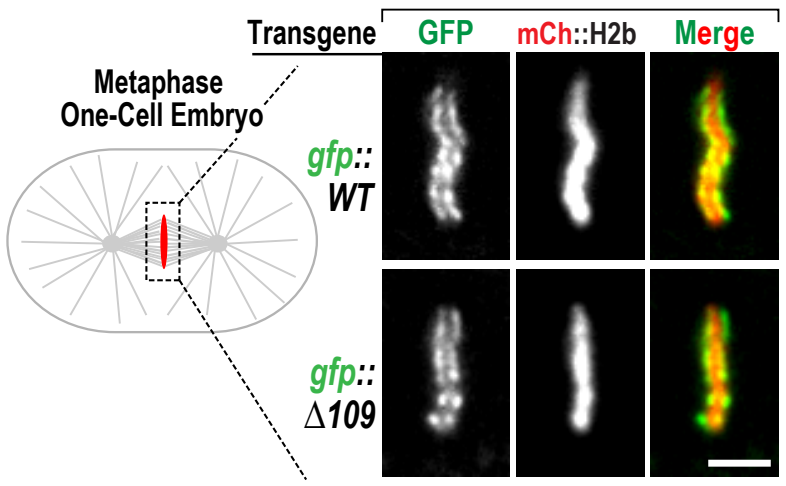

D

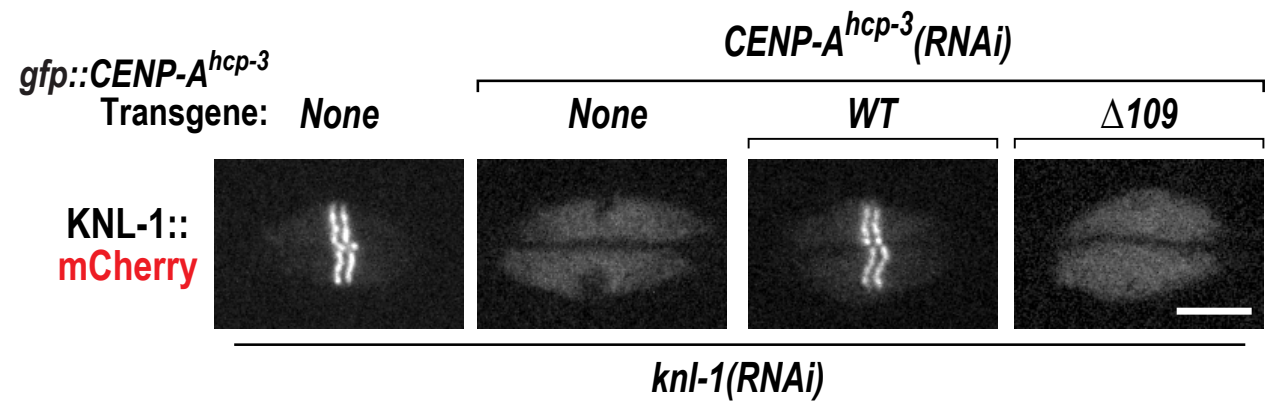

Endogenous CENP-A ${ }^{\text {HCP-3 }}$ Depleted

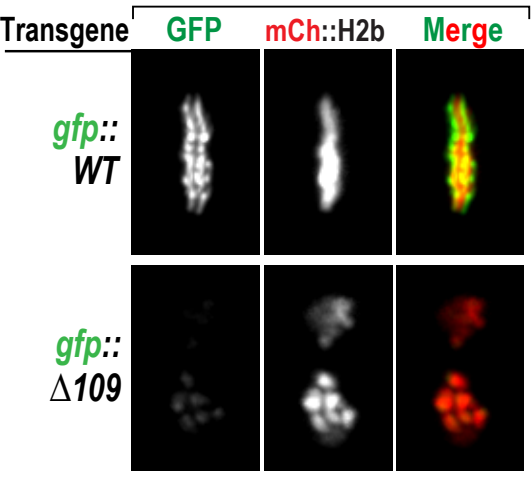

E

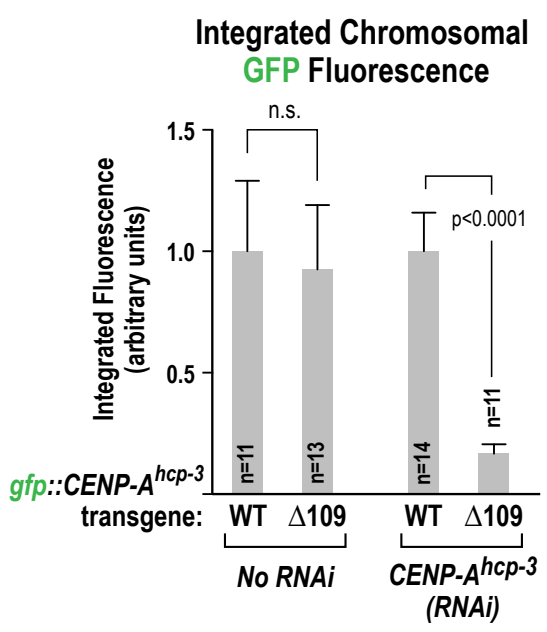

KNL-1::mCh Kinetochore Fluorescence

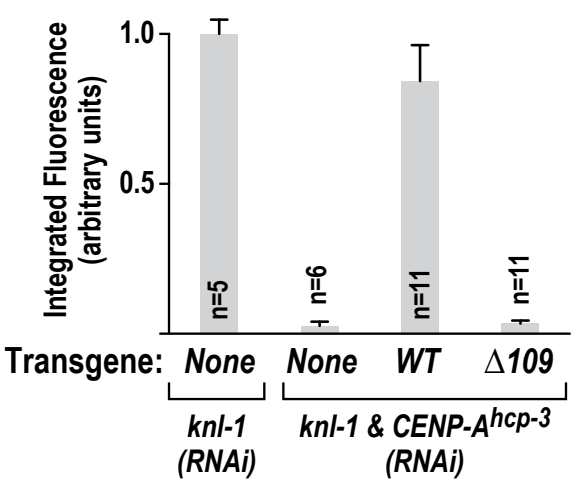


A

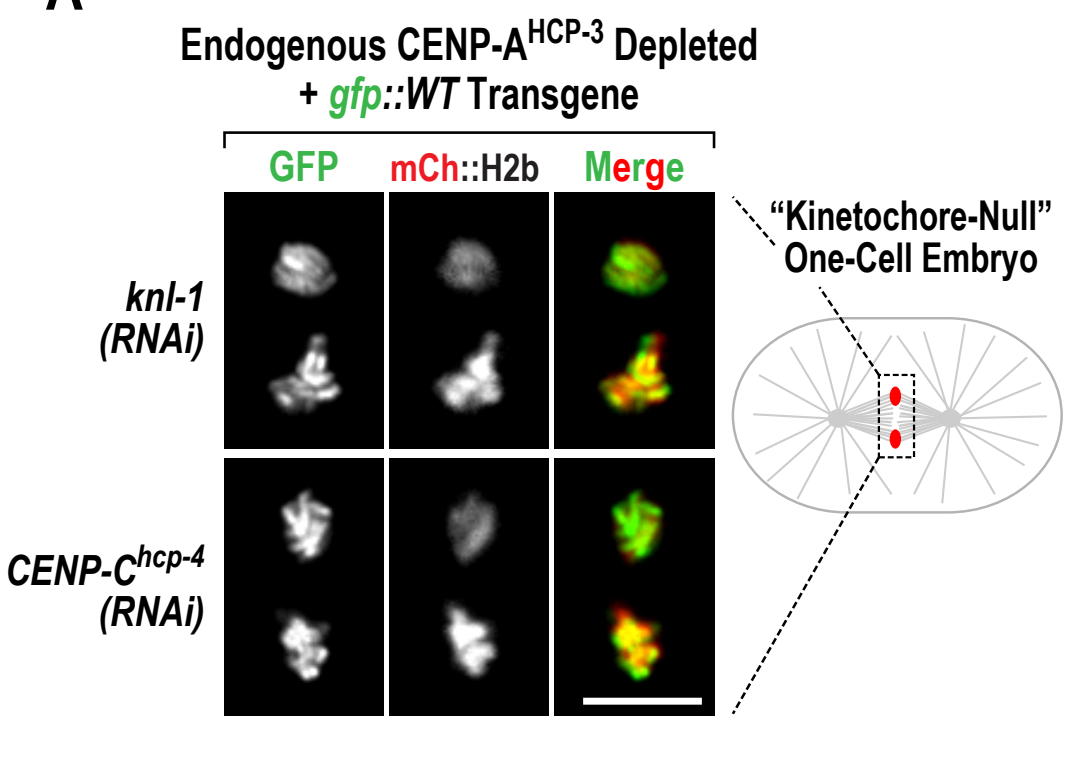

B

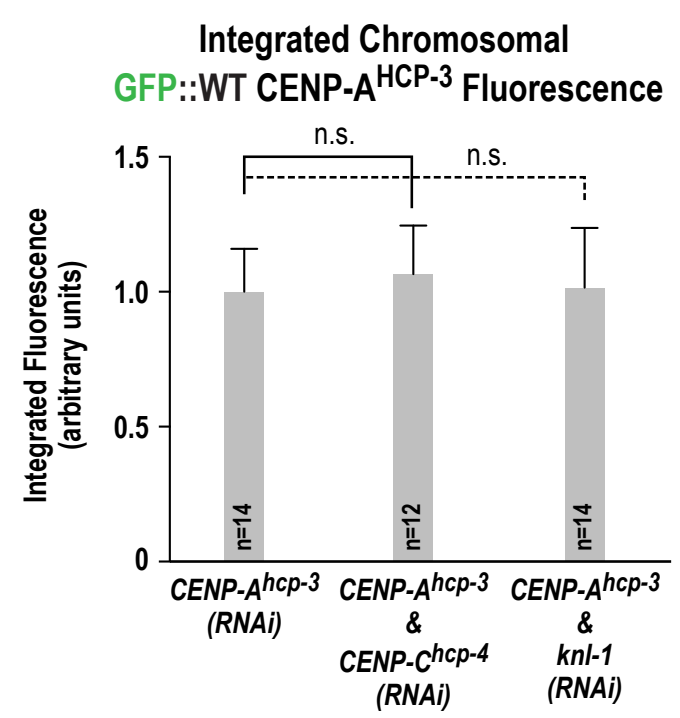

C

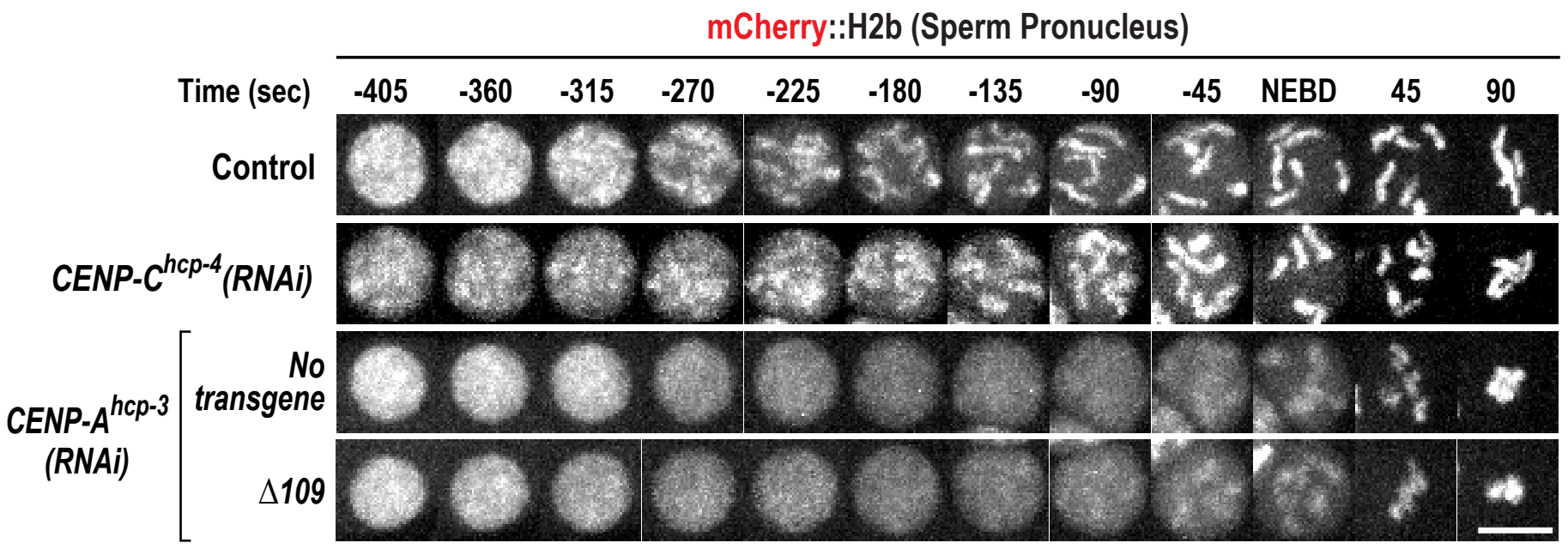


bioRxiv preprint doi: https://doi.org/10.1101/2020.12.28.424576; this version posted December 28, 2020. The copyright holder for this preprint (which was not certified by peer review) is the author/funder, who has granted bioRxiv a license to display the preprint in perpetuity. It is made available under aCC-BY-NC-ND 4.0 International license.

de Groot, Houston et al. Figure 4

A

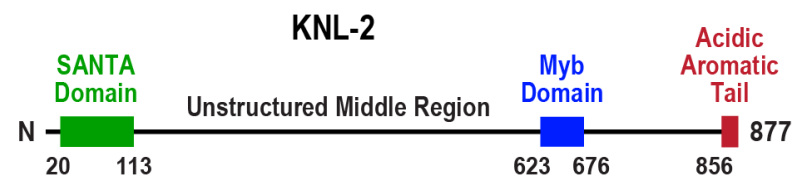

C

B

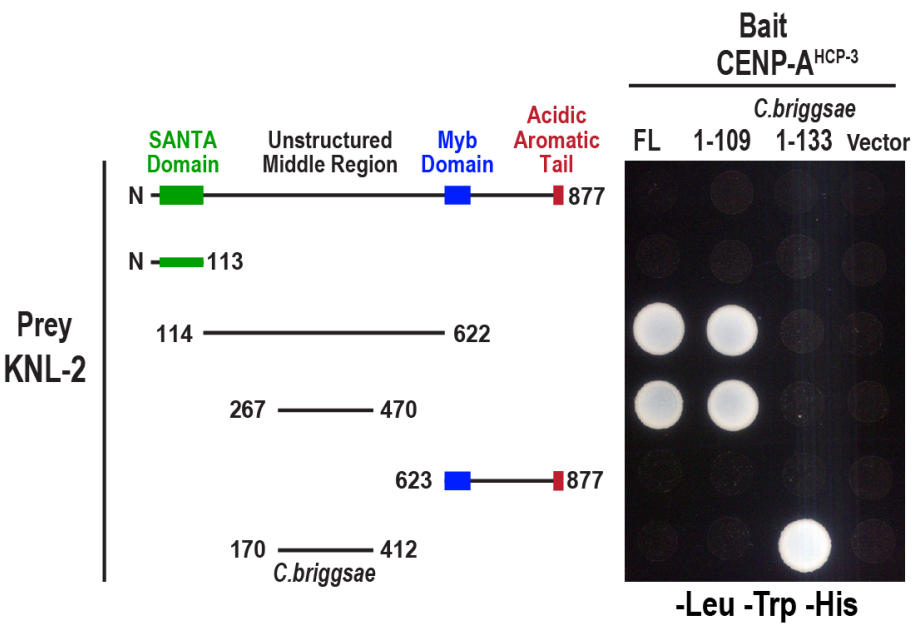

D

KNL-2 fragments

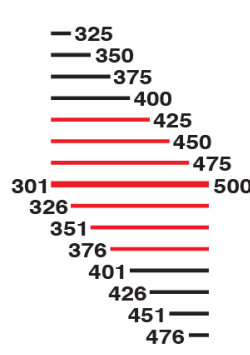

in vitro translated MBP-KNL-2 fragments

301- 301- 301-301-301-301-301-301-326-351-376- 401- 426- 451- 476325350375400425450475500500500500500500500500

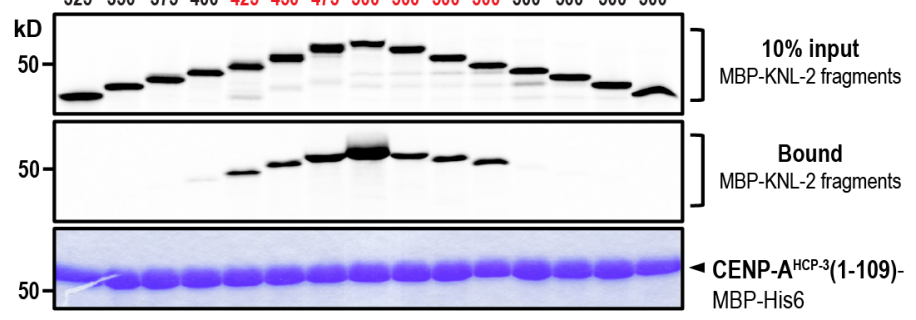

Overlapping KNL-2 fragments (in vitro translated)

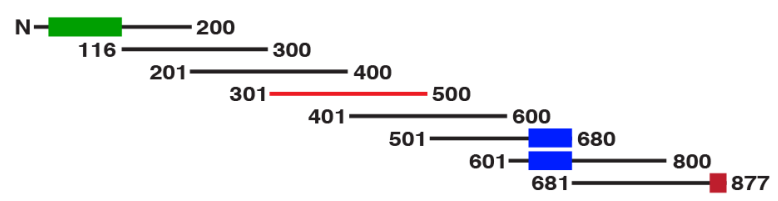

MBP-KNL-2 fragments

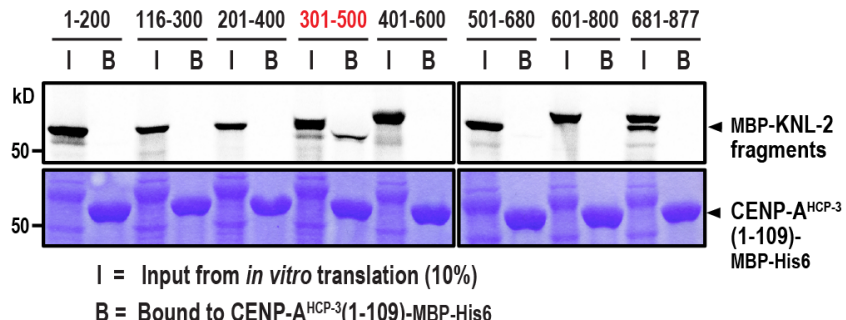

E in vitro translated MBP-KNL-2 fragments

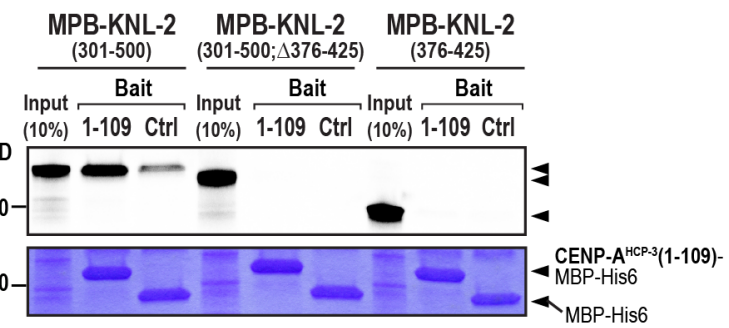


bioRxiv preprint doi: https://doi.org/10.1101/2020.12 28.424576; this version posted December 28, 2020. The copyright holder for this preprint (which was not certified by peer review) is the author/funder, who has granted bioRxiv a license to display the preprint in perpetuity. It is made available under aCC-BY-NC-ND 4.0 International license.

\section{de Groot, Houston et al. Figure S1}

\section{Single copy RNAi-resistant transgene encoding GFP::CENP-A ${ }^{\text {HCP-3 }}$}

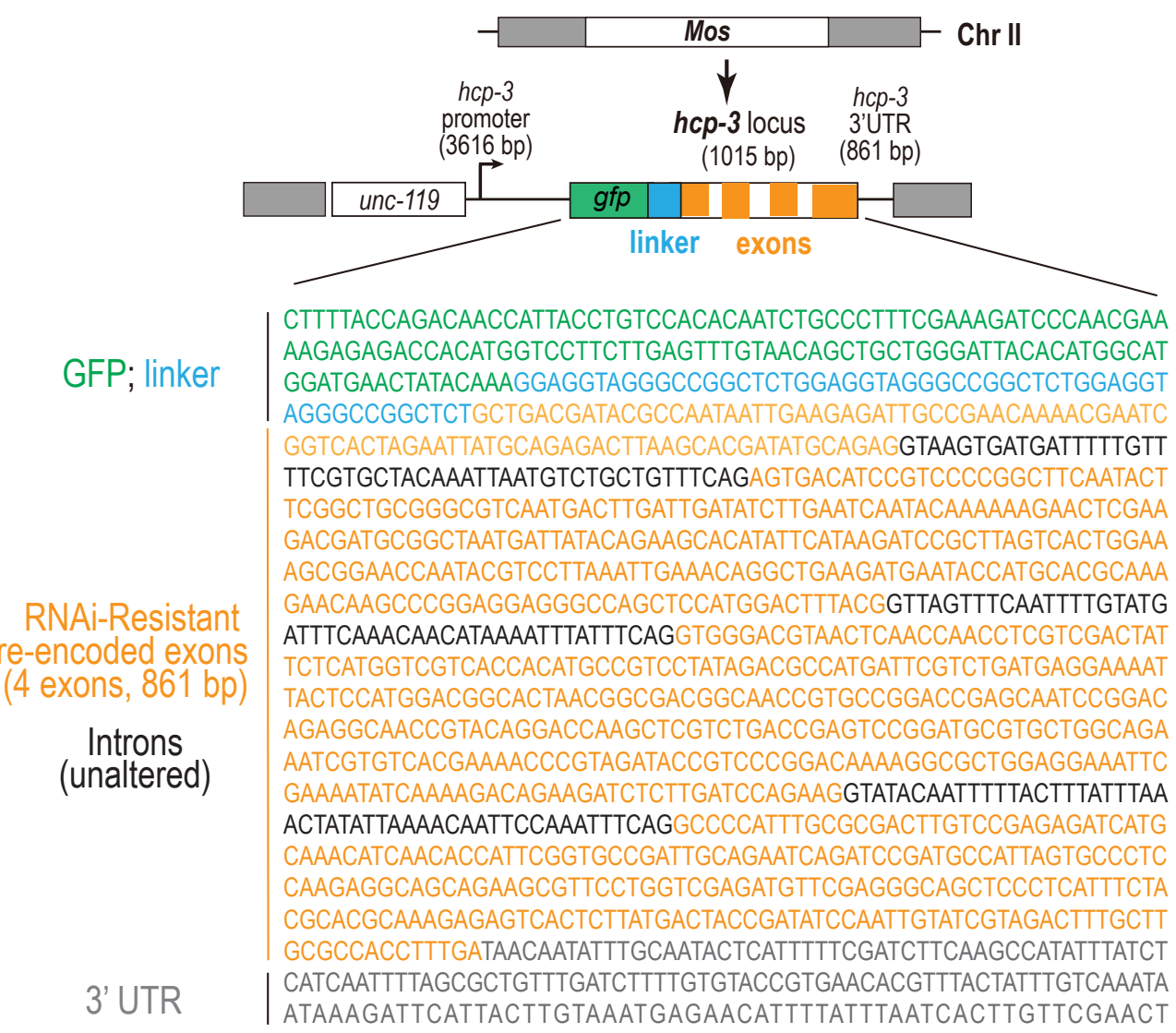


bioRxiv preprint doi: https://doi.org/10.1101/2020.12.28.424576; this version posted December 28, 2020. The copyright holder for this preprint

A

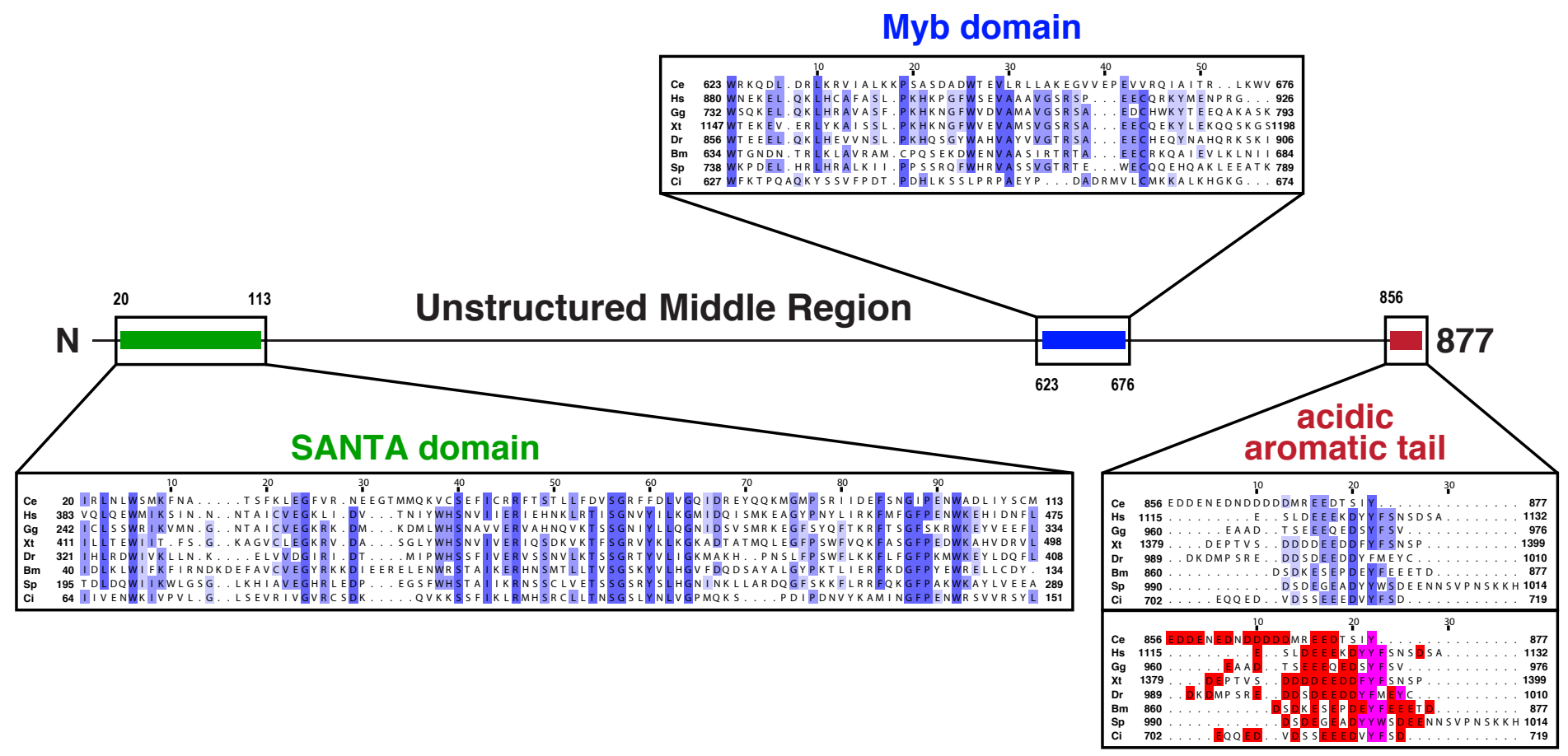

B

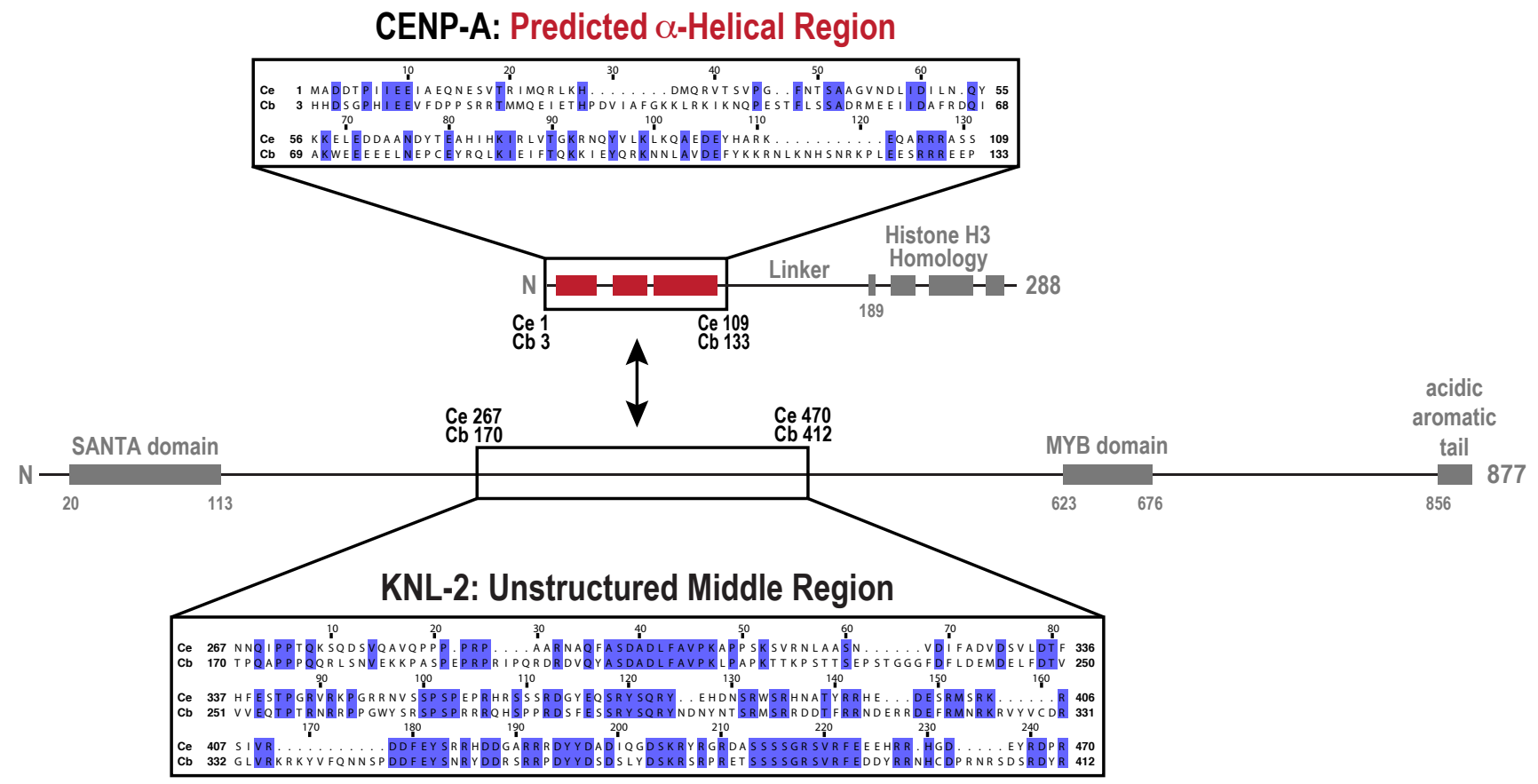

